\title{
2021 Academic Year opening speech
}

\section{Discurso inaugural del año académico 2021}

\author{
José Halabe-Cherem* \\ Postgraduate Education Division, Faculty of Medicine, Universidad Nacional Autónoma de México, Mexico City, Mexico
}

Distinguished academicians, ladies and gentlemen Members of the Board

Today, the National Academy of Medicine of Mexico (ANMM - Academia Nacional de Medicina de México) 2021 academic year is opened, and I am aware of what this commitment represents. The institution has more than 160 years of existence that reflect the history of multiple aspects of health in Mexico. The most brilliant minds in Mexican medicine have passed through the ANMM, including the presidents we can see portrayed here, as well as the talented academicians who were part of its boards of directors and, in general, each one of the members of this institution.

The ANMM picks this tradition up and updates it, taking on present and future challenges. For decades, the institution has been one of the most recognized voices on public health issues and this is tangible by its representation in the most important decision-making bodies of the national health system. On the other hand, the Academy is a recognized forum for the presentation of cutting-edge clinical, basic and socio-medical research, which is expounded and commented on by academicians on a weekly basis. The ANMM also has one of the most important medical publications of Mexico, Latin America and the world, Gaceta Médica de México, which has been steadily published and contains relevant works that analyze the knowledge related to our discipline in the field of health.

The heritage we are recipients of provides us with a great platform that allows us to continue growing and contributing better ideas to help with projects that impact medical practice. The ANMM is structured by differentiated sections of specialties that deal with academic, healthcare and research issues related to their knowledge and specific problems. One of the goals is to have the largest number of academicians from our institution actively participate, since they are experts in their professional areas.

The proposal of this board of directors is to give academicians a voice and make their knowledge visible. For this purpose, we will form committees for each specialty group, in order for them to raise the problems and possible solutions their corresponding areas face; this way, we expect to be inclusive and take advantage of talent in favor of Mexican medicine. With this intention, in the next few weeks, we will be convoking various groups of academicians from all over the Mexican Republic to form these committees. The purpose is to discuss and make proposals for change in consensuses on health policies. At the same time, we will strengthen the work of already existing committees, which have contributed valuable ideas in recent years. I invite the members of the Academy who are interested in participating to approach us to join these working groups.

One of the characteristics of the Academy is its plural composition. In the Academy, different organizations, ideological positions and varied ways of thinking about the contemporary world converge, which will be discussed and weighed in extraordinary general assemblies, on the board of directors and with the advisory body composed of our former presidents, to whom we will request their opinion owing to the baggage of experience they possess. Once a position has been agreed upon, the Academy will be able to issue its opinion and communicate it to the corresponding agencies. 
Regarding ANMM activities, the weekly sessions scheduled one year in advance will continue, as you will be able to see in the program to be found in the lobby of this auditorium; in addition, in these same forums, new academicians' admission works will be presented. The extramural sessions will be held with different health institutions, both public and private. We hope that these sessions can be simultaneously face-to-face and virtually held, in order to promote dialogical exchange. In this pandemic, we have learned that virtual communications can have a larger audience and offer the possibility of being consulted at any time.

We will strengthen distance education by means of videos aimed at the general practitioner and all different medical specialties. In addition, we will continue with the COVID-19 pandemic updating; from March 2020 to date, we have communicated the emerging scientific advances and their transformations to the medical community and the general population. We will closely follow emerging and re-emerging diseases, so that, with our academician experts, we can propose guidelines or measures to be followed. We will continue to work closely with the National Autonomous University of Mexico (UNAM - Universidad Nacional Autónoma de México) in general and with the Faculty of Medicine in particular, on different educational programs both at undergraduate and postgraduate level. We will also be collaborating on these same aspects with medical schools and faculties of the country.

Gaceta Médica, as the ANMM official journal, is a publication whose impact index increases day by day. Visits from all parts of the world are increasingly numerous, since the articles are published in English and Spanish. Currently, the journal is accessible only online, which saves both natural and financial resources. The rigor in the article selection process continues to be highly strict, and thus will it continue in order to maintain editorial quality. Gaceta has an adequate balance on its content (editorials, clinical case reports, monographs, research articles and letters to the editor). We will suggest for a section called "reflection articles" to be added in order to accommodate analytical proposals of interest in the field of health. The list of prominent reviewers who collaborate with Gaceta Médica will be strengthened with new members in order to confer dynamism to the discussion of ideas. The ANMM editorial committee will evaluate, discuss and, where appropriate, approve the publication of books and printed and digital materials endorsed by our organization.

Regarding the annually-granted awards, a new one will be added, aimed at recognizing merits in health sciences education. The purpose is to stimulate the work of teachers in the transmission of knowledge and the training of human resources that allow the reproduction of the medical field.

The ANMM can become a strong node in the network of national and international health institutions. Today, our academicians hold important positions in the country's public life; for example, the Secretary of Health, the UNAM rector, the permanent ambassador of Mexico before the United Nations, the director of UNAM Faculty of Medicine, among others, with whom we will interact to enhance academic work of the Academy. In this same sense, we will strengthen relationships with the national academies of the United States, Spain and France, as well as with various Central and South American countries we have reached some agreements with.

Having worked during these two years as vice president allowed me to closely learn about the dynamics of the institution. Daily work, the achievements and the problems we faced drove us to form a supportive team that, beyond our organization, generated strong ties of friendship. The board we are members of today -made up of Dr. Germán Fajardo as Vice President, Dr. Mayela Rodríguez as Secretary, Dr. Miguel Abdo as Treasurer and Dr. José Flores as Deputy Secretary, as well as the entire ANMM team- is committed to working arduously to the benefit of Mexican medicine.

Distinguished academicians, I invite you to work in unison and to contribute our knowledge and experience to make the ANMM great.

I thank you for your attention, your trust, and I know that I will count on each one of you. 